\title{
Analysis of biomechanical effectiveness of valgus-inducing knee brace for osteoarthritis of knee
}

\author{
Thomas Schmalz, PhD; ${ }^{1 *}$ Elmar Knopf, MD; ${ }^{2}$ Heiko Drewitz, CPO; ${ }^{1}$ Siegmar Blumentritt, PhD $^{1-2}$ \\ ${ }^{1}$ Otto Bock Healthcare, Department of Research, Duderstadt, Germany; ${ }^{2}$ Orthopaedic Department, Georg August \\ University, Göttingen, Germany
}

\begin{abstract}
The biomechanical effectiveness of a valgusinducing knee brace was investigated for 16 patients with knee osteoarthritis (mean +/- standard deviation age $56+/-10 \mathrm{yr}$, height $172+/-9 \mathrm{~cm}$, mass $83+/-7 \mathrm{~kg}$, body mass index $27.6+/-$ $4.5 \mathrm{~kg} / \mathrm{m}^{2}$ ). At the time of investigation, all subjects had been wearing the brace for at least 4 weeks. In addition to conducting standard gait analysis, we calculated the valgus moment generated by the brace by using a novel system that measured the actual deformation of the brace during stance phase and determined the reaction force created by the brace on the leg. The mean maximum value of the orthotic valgus moment was $0.053 \mathrm{Nm} / \mathrm{kg}$, which represents approximately $10 \%$ of the external genu varus moment without the brace. This finding may explain the pain relief reported by patients using such braces in clinical studies. Use of the tested brace also decreased the magnitude of gait asymmetry between the braced and contralateral legs during walking (horizontal ground reaction force, external knee flexion moment), presumably because the subjects' need to walk abnormally to shield the knee from pain was reduced.
\end{abstract}

Key words: biomechanics, gait analysis, knee loading, knee osteoarthritis, orthopedics, orthotics, pain, rehabilitation, valgus bracing, visual analog scale.

\section{INTRODUCTION}

Osteoarthritis of the knee is one of the most common joint diseases. The incidence of painful arthritic knees increases significantly from the third decade onward [1].
Epidemiological studies show that approximately 5 to 6 percent of the population present clinically with painful knee osteoarthritis [1]. Treatment may be by operative and nonoperative methods. In addition to arthroscopy, operative treatments include joint replacements and osteotomies. Nonoperative treatments are usually offered in mild to moderate cases or when surgery is not feasible, and may include drug therapies, physiotherapeutic measures, and orthopedic devices (walking aids, orthopedic inserts, shoe sole elevations, knee braces). According to the most recent analysis, less than 1 percent of all patients with knee osteoarthritis are fitted with a knee brace [2].

The clinical effectiveness of this medical device has been reported in previous studies (i.a., [3-8]). However, studies published to date show conflicting results regarding the biomechanical mechanism of the knee brace.

Many studies have shown that the external varus moment is a suitable indicator of knee joint loading,

Abbreviations: $\mathrm{BW}=$ body weight, $\mathrm{SD}=$ standard deviation, VAS = visual analog scale, $\mathrm{WB}=$ with brace, $\mathrm{WOB}=$ without brace.

*Address all correspondence to Thomas Schmalz, PhD; Otto Bock HealthCare GmbH, Forschungs-und Entwicklungswerkstatt, Labor für Biomechanik, Hermann-ReinStraße 2a, D-37075 Göttingen, 05513075131 Germany; fax: 0049-551-3075134. Email: schmalz@ottobock.de DOI:10.1682/JRRD.2009.05.0067 
which is increased in the majority of cases with varus deformities secondary to knee osteoarthritis [9-13]. Scientific investigations of the effect of a knee brace on the external varus moment report either a reduced varus moment [14-16] or no significant change in this biomechanical parameter [17-19]. These contradictory results raise questions about whether or not forces produced by knee braces are sufficient to significantly alter the external moment.

A number of researchers have suggested that braces for treating varus knee osteoarthritis generate a valgus moment, partially compensating for the external varus moment $[15,20]$ and, therefore, reducing the need for the muscles and ligaments to counteract the pathological forces [21]. This mechanism is also believed to result in reduced joint force within the medial compartment, reducing pain symptoms [20-21].

Given the contradictory theories and findings, analyzing the external varus moment in the gait laboratory appears to be inadequate to provide evidence about the in vivo function of a knee osteoarthritis brace. For this rea- son, previous studies have used specially designed test braces with highly precise integrated sensors to directly measure the valgus moment created by the brace [16,20,22].

In contrast, this article introduces a method for determining the valgus moment without an instrumented test brace. The approach presented here uses each patient's individual brace without modification. Using the prescribed, fitted brace worn by each person provides more direct evidence about the actual effect of the brace in vivo. The overall goal of this study is to add to the body of knowledge regarding the biomechanical basis for valgus-inducing knee braces.

\section{METHODS}

\section{Patients}

Sixteen patients (eight male, eight female) diagnosed with medial knee osteoarthritis by orthopedists were recruited for this study (Table 1). The clinical criteria for

Table 1.

Data for participants with knee osteoarthritis wearing valgus-inducing brace.

\begin{tabular}{|c|c|c|c|c|c|c|c|c|}
\hline Patient & Sex & Age (yr) & Height (cm) & Mass (kg) & BMI & $\begin{array}{c}\text { Wearing } \\
\text { Duration } \\
\text { (wk) }\end{array}$ & $\begin{array}{c}\text { Wearing } \\
\text { Time (h/d) }\end{array}$ & $\begin{array}{c}\text { Walking } \\
\text { Distance } \\
(\mathbf{k m} / \mathbf{d})\end{array}$ \\
\hline 1 & $\mathrm{M}$ & 60 & 148 & 78 & 23.1 & 4 & 12.0 & 6.0 \\
\hline 3 & $\mathrm{~F}$ & 45 & 157 & 57 & 23.0 & 6 & 9.0 & 6.0 \\
\hline 4 & $\mathrm{~F}$ & 41 & 178 & 72 & 22.7 & 4 & 9.0 & 8.5 \\
\hline 6 & F & 62 & 158 & 67 & 26.8 & 6 & 11.0 & 2.0 \\
\hline 7 & $\mathrm{~F}$ & 65 & 172 & 65 & 22.1 & 164 & 10.0 & 7.5 \\
\hline 8 & $\mathrm{~F}$ & 59 & 167 & 100 & 35.8 & 4 & 12.0 & 7.5 \\
\hline 9 & $\mathrm{~F}$ & 67 & 171 & 94 & 32.0 & 4 & 8.0 & 5.5 \\
\hline 10 & M & 61 & 170 & 92 & 31.8 & 8 & 6.0 & 3.5 \\
\hline 14 & M & 50 & 192 & 92 & 25.0 & 21 & 16.0 & 6.5 \\
\hline 15 & $\mathrm{~F}$ & 67 & 176 & 82 & 26.6 & 60 & 10.0 & 5.0 \\
\hline 16 & M & 64 & 179 & 86 & 26.8 & 52 & 2.0 & 1.0 \\
\hline Mean & - & 56 & 172 & 83 & 27.9 & 22 & 9.6 & 5.3 \\
\hline SD & - & 9 & 9 & 12 & 4.5 & 42 & 3.2 & 2.2 \\
\hline Min & - & 41 & 157 & 57 & 22.1 & 4 & 2.0 & 1.0 \\
\hline Max & - & 67 & 192 & 100 & 36.5 & 164 & 16.0 & 8.5 \\
\hline
\end{tabular}

BMI = body mass index, $\mathrm{F}=$ female, $\mathrm{M}=$ male, $\mathrm{Max}=$ maximum, Min = minimum, $\mathrm{SD}=$ standard deviation. 
diagnosis of osteoarthritis included radiological assessment combined with patient reports of knee swelling, morning stiffness, pain during ambulation, or joint stiffness. An experienced orthopedist grouped the patients according to the osteoarthritis classification system developed by Kellgren and Lawrence [23]. One patient was assigned to level 1 , five patients to level 2, seven patients to level 3, and three patients to level 4 .

All patients had been previously prescribed by their treating physician the knee brace used in this study for treatment of their osteoarthritis and had worn it daily for a minimum of 4 weeks at the time of testing. The 4-week period was considered sufficient to verify wearing compliance and permit adequate acclimation to the brace (Table 1). Exclusion criteria for the study included recent injuries, skin disorders, varicosities, and diseases other than knee osteoarthritis influencing the gait pattern.

All patients signed an informed consent to participate in this study. Each recruited patient traveled to the gait laboratory for one measurement session. In addition to the biomechanical measurements, they were asked to give a short subjective assessment of the effect of the brace.

\section{Functional Description and Fitting Procedure of Tested Knee Brace}

The patients used the Genu Arthro knee brace, which has a unilateral sidebar design (Otto Bock; Duderstadt, Germany [Figure 1]). The Genu Arthro brace is a prefabricated system that is individually adjusted to each patient's body measurements. All brace fittings were conducted by the same qualified and experienced orthotist.

The pain-relieving function of this brace is based on the classic three-point pressure principle. Thigh and shank segments are connected by a single axis joint on the lateral side of the leg. An adjustment mechanism permits variable positioning of the thigh segment in the coronal plane while the patient is standing (Figure 2). Once the brace has been individually adjusted, reaction forces will be generated on the thigh depending on the magnitude of the adjustment.

At the beginning of the treatment phase, the brace adjustment was optimized for each patient according to his or her individual needs. The most important criterion for this procedure was the patient's tolerance of the valgus forces resulting from the coronal plane adjustments, as illustrated in Figure 2. After the patients were recruited into this study, the individual adjustment of the

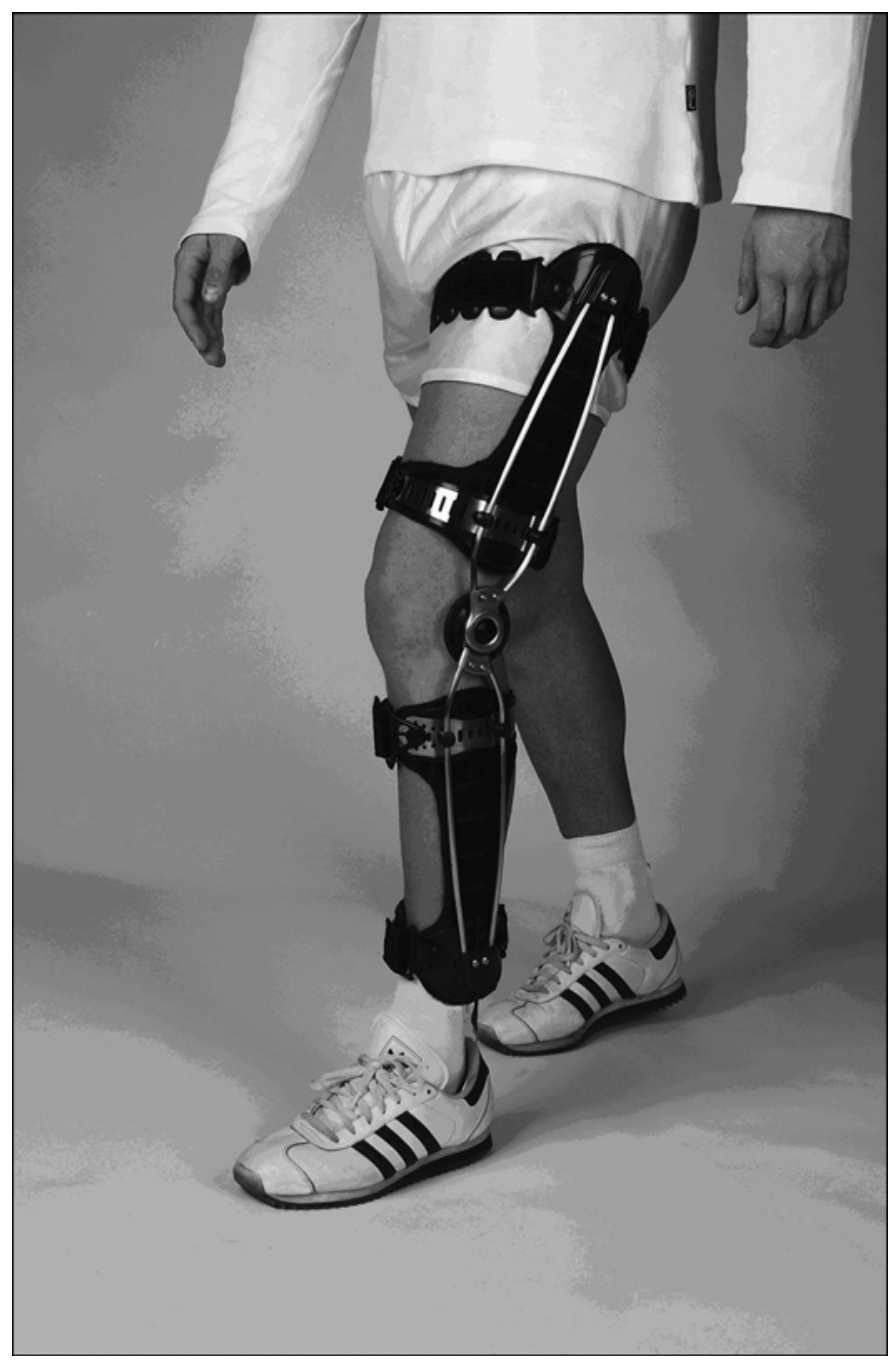

Figure 1.

Patient wearing Genu Arthro valgus-inducing knee brace used in study.

valgus force was evaluated and modified as needed before the measurement session began.

\section{Subjective Assessment}

Before the biomechanical investigations, the patients were queried about their medical history and perceptions of the quality of brace fitting. Subjects were asked to assess the fit of the brace, wearing comfort of the components, appearance, and ease of use on a scale ranging from 0 ("very poor") to 6 ("very good"). Patient selfreports of daily wearing time were recorded to assess compliance in wearing the brace. Pain while walking was measured with a visual analog scale (VAS) ranging from 0 (“no pain”) to 10 (“worst pain imaginable”). 


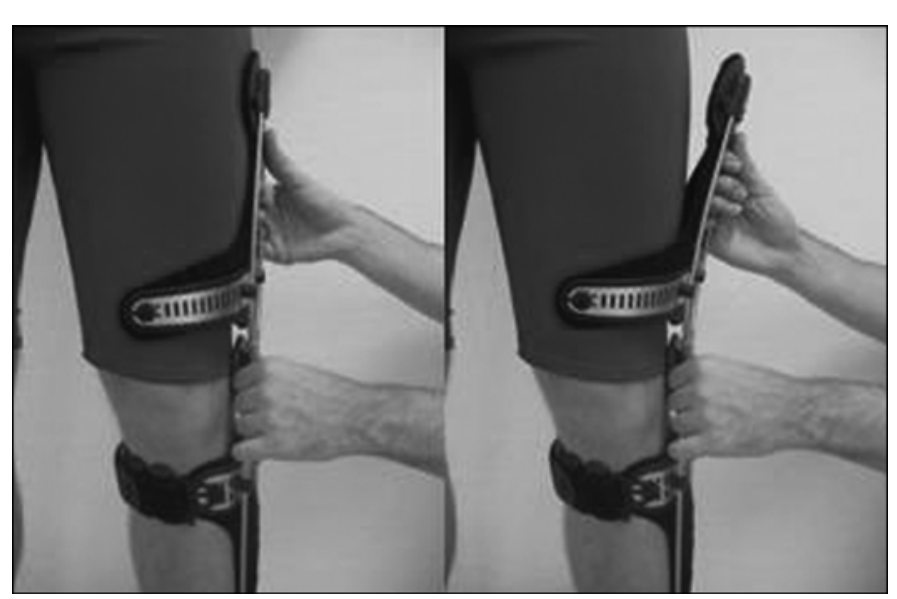

Figure 2.

Different basic adjustments to Genu Arthro brace. Left: low deformation = low valgus moment after cinching up thigh section; right: strong deformation $=$ high valgus moment after cinching up thigh section.

\section{Biomechanics}

\section{Standard Gait Analysis}

Gait analysis was conducted under two conditions: without brace (WOB) and with brace (WB), in random order. For the WB condition, an additional static measurement was recorded without the thigh portion of the brace secured to the leg. Eight to ten walking trials were recorded for each condition.

Measurement of ground reaction forces during walking was conducted bilaterally with use of two force plates (measuring frequency $1,080 \mathrm{~Hz}$; Kistler; Winterthur, Switzerland). Motion kinematics were tracked by an optoelectronic six-camera system $(120 \mathrm{~Hz}$; Vicon; Oxford, United Kingdom) with use of passive reflective markers fixed to anatomical reference points. The marker set used comprises seven markers for each side of the body (acromioclavicular joint, lateral epicondyle of elbow, wrist, greater trochanter, lateral femoral condyle, lateral malleolus, and fifth metatarsal head). External moments acting on the major joints of the lower limb were calculated based on kinematic data and ground reaction forces with use of Vicon Body Builder 3.5 software.

\section{Determination of Valgus Moment Produced by Brace}

The moment created by the brace can be determined from the reaction force acting on the proximal force application point of the brace and from the effective lever arm. The effective lever arm results from the functional length of the thigh module (Figure 3(a)).

The first step was to determine the relationship between the reaction force of the brace $F_{b r}$ and the resulting frontal deformation of the brace by means of a simple, self-developed force-measuring station (Figure 3(a)). With this station, the force acting at the proximal edge of the thigh piece ( $P$ in Figure 3(a) and (c)) is transferred directly by a cord and pulley assembly so it can be measured by a spring dynamometer (SDM, Hahn-Kolb; Stuttgart, Germany).

Before gait analysis, the displacements $X_{i}$ of the point $P$ resulting from the acting forces were determined by means of a simple linear scale (Figure 3(c)). After recording a set of 15 to 18 pairs of values for $F_{b r}$ and $X_{i}$ for each brace, we found the following linear relationship (Figure 3(b)-(c)):

$$
F_{\mathrm{br}}=C_{\mathrm{br}} \times \Delta X_{i} \text { with } \Delta X_{i}=\left|X_{i}-X_{0}\right|,
$$

where $X_{0}=$ initial position in unloaded condition, $X_{i}=$ change in distance compared to unloaded condition, $F_{\mathrm{br}}=$ reaction force, and $C_{\mathrm{br}}=$ stiffness of brace, $i=1 \ldots(15$ ... 18).

Based on this correlation, the stiffness of each individually adjusted brace $C_{\mathrm{br}}$ could be defined by means of a regression calculation (example is shown in Figure 3(b)).

Once the individual value for $C_{\mathrm{br}}$ has been determined, the valgus moment of the brace can be determined from gait laboratory data. Measuring the specific deformation of each brace during the WB gait analysis enabled calculation of the biomechanical effect of the device in the frontal plane.

Three additional markers were attached to the brace for this purpose (uniaxial hinge, proximal, and distal end of the brace). Based on the three-dimensional coordinates of these markers, deformation (relative to the static measurement taken before the thigh segment was cinched down) was determined with use of simple trigonometric calculations. This deformation, combined with the stiffness $C_{\text {Orth }}$ permits calculation of the reaction force and associated moment created by the brace. The brace valgus moment was calculated during the first 50 percent of the gait cycle, when knee joint loading is of particular interest. 
(a)
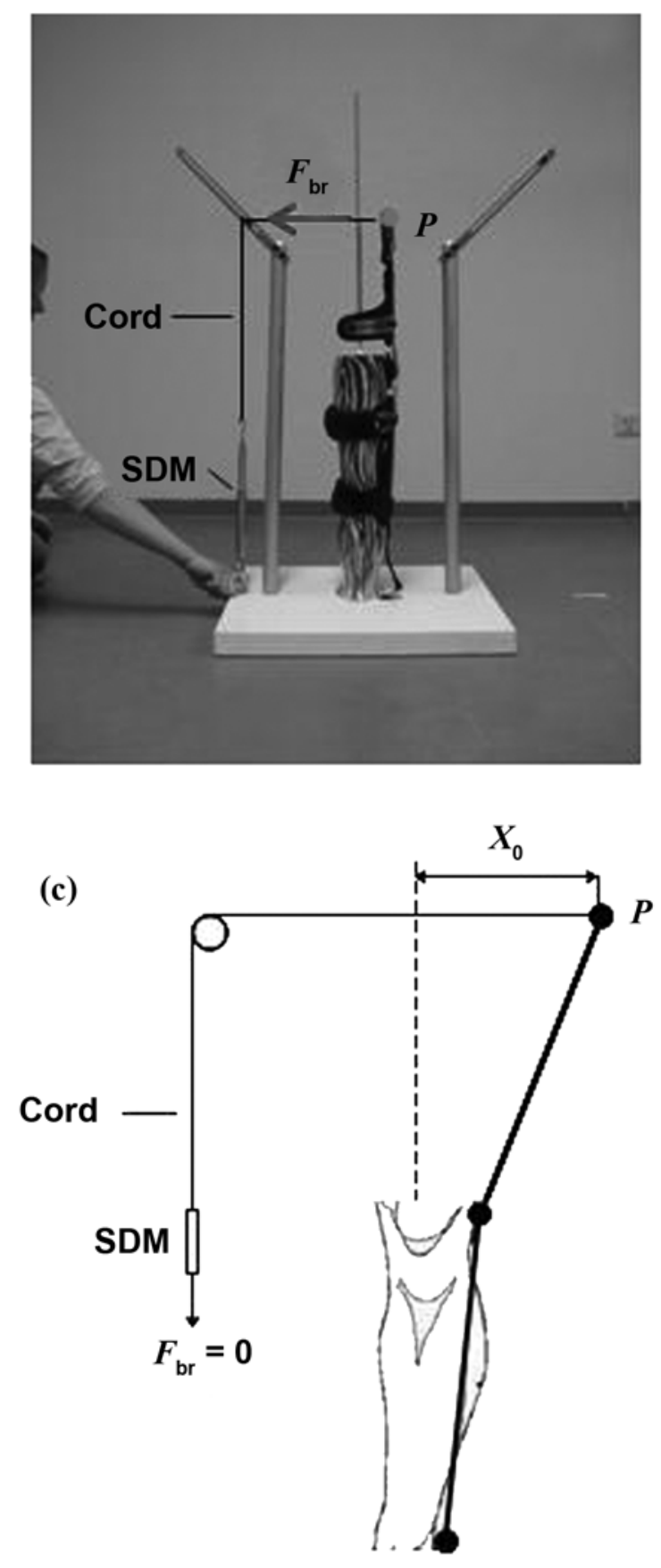

(b)
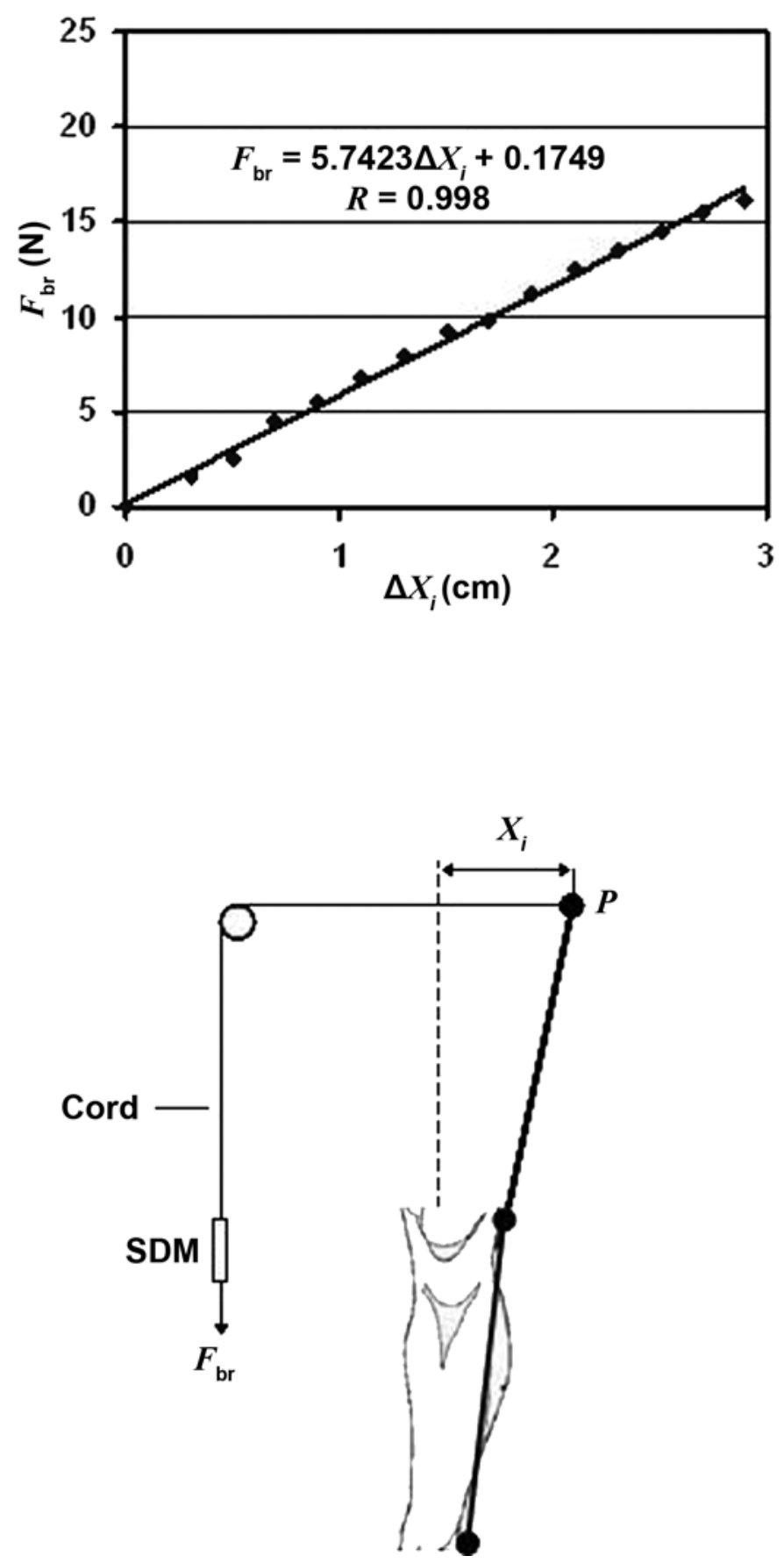

Figure 3.

(a) Force measuring station for defining stiffness of brace, (b) individual example demonstrating relation between reaction force of brace leading to deformation according to equation in main text, and (c) demonstration of measurement principle. $F_{\mathrm{br}}=$ force on brace, $P=$ proximal force application point, SDM = spring dynamometer.

Data Processing

Mean values standardized to the gait cycle were derived for all biomechanical parameters for each subject. Mean group values were then calculated, permitting 
comparison between both conditions and between the arthritic and contralateral limbs. Significant differences between the peak values of key biomechanical parameters were determined by the Wilcoxon test.

\section{RESULTS}

\section{Subjective Assessment}

On the basis of the mean \pm standard deviation (SD) $8.9 \pm 3.4 \mathrm{~h} / \mathrm{d}$ duration of use reported, we consider these subjects highly compliant in wearing the brace. The mean \pm SD pain-with-walking VAS score of $6.4 \pm 1.7$ for the WOB condition was significantly reduced to $3.3 \pm 1.9$ for the WB condition $(p \leq 0.01)$. Subjective evaluations of the knee brace-with the exception of wearing comfort at the thigh-were very favorable, with average scores ranging between 4.3 ("good") and 4.9 ("very good"). The average value of 3.4 for wearing comfort at the thigh may have resulted from the intermittent feeling of slipping of the brace reported by six subjects.

\section{Biomechanics}

\section{Time-Distance Parameters}

The mean walking speed significantly increased from $1.27 \mathrm{~m} / \mathrm{s}$ WOB to $1.36 \mathrm{~m} / \mathrm{s}$ WB $(p \leq 0.01)$. Cadence WB increased significantly compared with WOB, from 107 to 110 steps/min $(p \leq 0.01)$. The step length for the arthritic limb increased from $0.71 \mathrm{~m}$ WOB to $0.73 \mathrm{~m} \mathrm{WB}$, while step length of the contralateral limb reduced from 0.75 to $0.73 \mathrm{~m}$ (Table 2).

\section{Ground Reaction Force}

The analysis of the vertical component of the ground reaction force (Figure 4(a)) shows that vertical loading decreases between 5 and 15 percent of the gait cycle on the arthritic limb WOB when compared with the contralateral leg or with the WB condition. The first vertical force maximum is also significantly decreased in the WOB condition compared with the WB condition (104\% vs $109 \%$ body weight [BW], respectively, $p \leq 0.05$ ).

Significant differences were also observed in the horizontal component of the ground reaction force during early stance phase, sometimes referred to as the "braking force" (Figure 4(b)). Compared with the contralateral limb, the horizontal force was significantly reduced WOB (14.3\% vs $17.9 \%$ BW, respectively, $p \leq 0.01)$. In the WB condition, the horizontal force on the leg affected by osteoarthritis increased by 16.4 percent BW, which is comparable to the horizontal force on the contralateral limb. No systematic differences could be identified in the mediolateral forces under any of the investigated conditions (Figure 4(c)).

\section{Biomechanical Characteristics of Knee Joint}

The knee flexion moments in the sagittal plane during the first part of stance phase are strikingly different between conditions. The mean maximum flexion moment for the contralateral knee was $0.45 \mathrm{~N} \cdot \mathrm{m} / \mathrm{kg}$ under conditions, while the mean maximum flexion moment for the arthritic knee WOB was significantly diminished to $0.23 \mathrm{~N} \cdot \mathrm{m} / \mathrm{kg}(p \leq 0.01)$. The maximum flexion moment for the arthritic knee WB increased to $0.33 \mathrm{~N} \cdot \mathrm{m} / \mathrm{kg}$, although this change was not statistically significant. (Figure 5(b)).

The limb loading characteristics of the affected limb are associated with reduced motion of the knee joint throughout the stance phase. Both stance phase flexion and stance phase extension on the affected limb were both reduced by approximately $3^{\circ}$ compared with the contralateral side (Figure 5(a)). This finding was true whether or not the brace was being worn.

The mean maximum value of the external varus moment $(0.53 \mathrm{~N} \cdot \mathrm{m} / \mathrm{kg})$ was the same regardless of the test condition for the contralateral limb. The mean maximum loading on the arthritic knee WOB increased to $0.63 \mathrm{~N} \cdot \mathrm{m} / \mathrm{kg}$, although this change was not statistically

Table 2.

Mean time-distance parameters for participants with knee osteoarthritis walking with brace (WB) and without brace (WOB).

\begin{tabular}{lcccc}
\hline \multirow{2}{*}{ Condition } & \multirow{2}{*}{ Walking Speed (m/s) } & Cadence (steps/min) & \multicolumn{2}{c}{ Step Length (m) } \\
\cline { 3 - 4 } & 1.27 & 107 & Osteoarthritic Limb & Nonosteoarthritic Limb \\
\hline WOB & $1.36^{*}$ & $110^{*}$ & 0.71 & 0.75 \\
WB & & $0.73^{\dagger}$ & $0.73^{\dagger}$ \\
\hline
\end{tabular}

* Significant difference between conditions, $p \leq 0.01$.

${ }^{\dagger}$ No significant difference between conditions. 
(a)
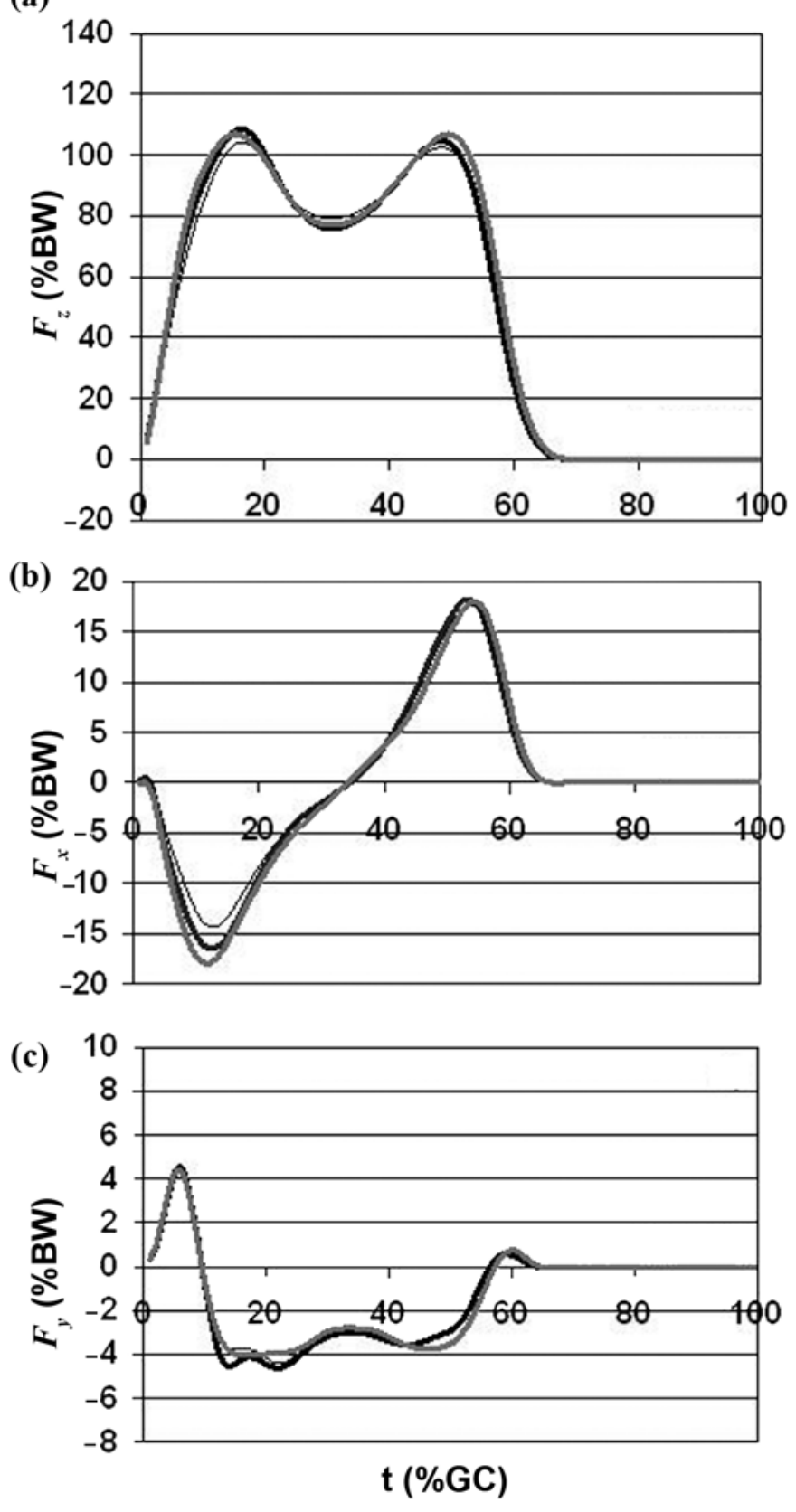

Figure 4.

Mean ground reaction force $(F)$ : (a) vertical component (z), (b) horizontal component $(x)$, and $(\mathbf{c})$ mediolateral component $(y)$. Gray $=$ nonarthritic contralateral limb (without brace [WOB]), thick black = arthritic limb with brace, and thin black = arthritic limb WOB. BW = body weight, $\mathrm{t}(\% \mathrm{GC})=$ time (\% gait cycle) .

significant (Figure 5(c)). Averaged values from gait analysis WB did not demonstrate any measurable changes for this parameter, similar to several prior studies.
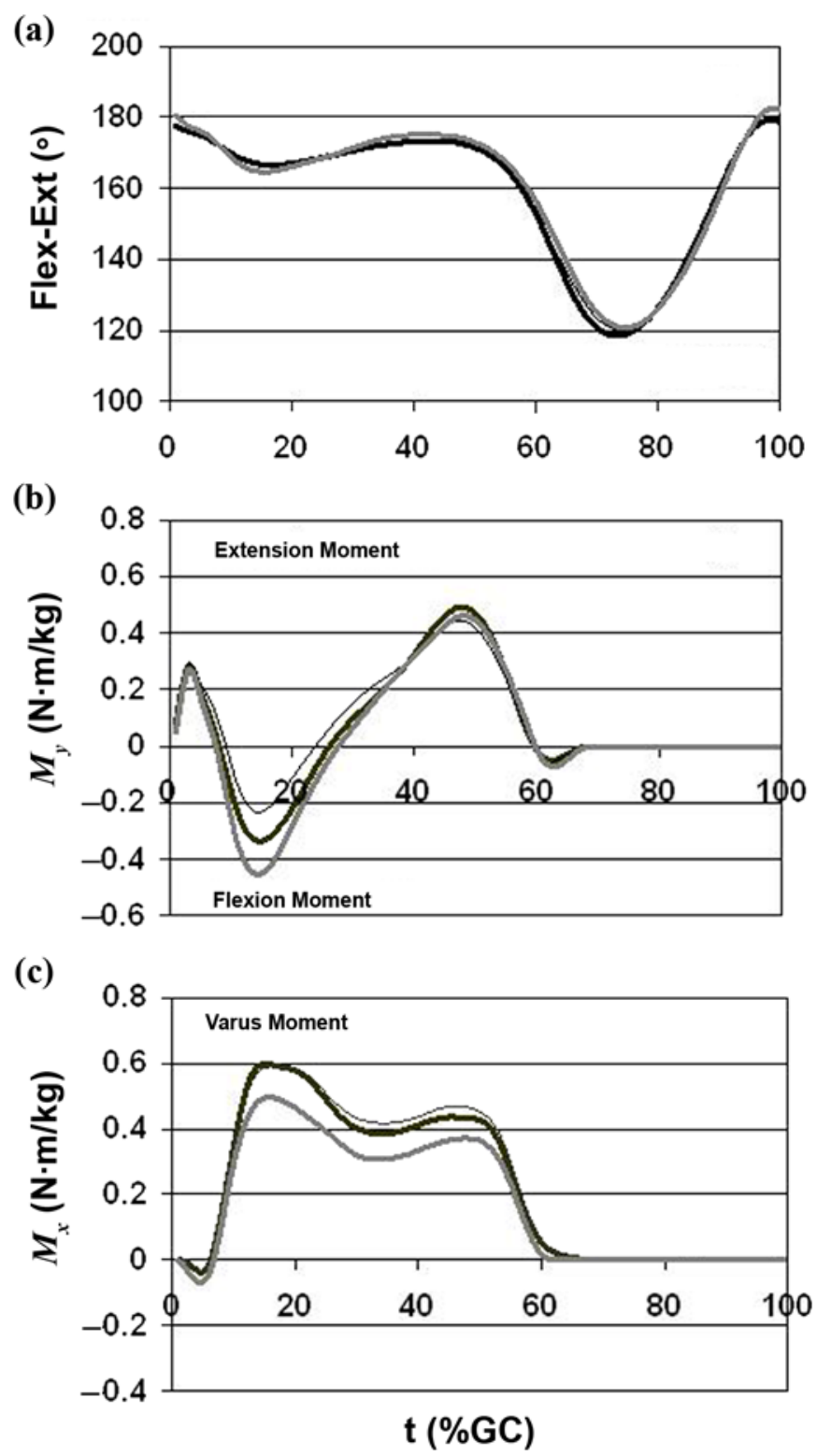

Figure 5.

Mean biomechanical knee parameters: (a) flexion-extension (FlexExt) angle, (b) stance phase external sagittal knee moment $\left(M_{y}\right)$, and (c) stance phase external varus knee moment $\left(M_{\chi}\right)$. Gray = nonarthritic contralateral limb (without brace [WOB]), thick black = arthritic limb with brace, and thin black = arthritic limb WOB. $\mathrm{t}(\% \mathrm{GC})=$ time $(\%$ gait cycle).

\section{Effect on Knee Joint of Moments Created by Brace}

The mean curve presented in Figure 6 illustrates the moment created by the braces during the first half of the gait cycle. The SD reflects important differences between individual results. The time during stance phase when maximum loading occurs also varied between subjects. 


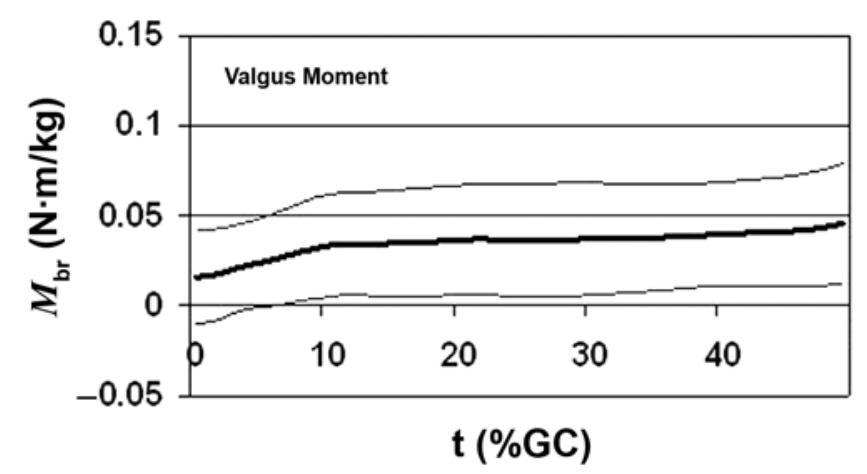

Figure 6.

Mean valgus moment of brace $\left(M_{\mathrm{br}}\right)$ for first 50 percent of gait cycle. Thick black $=$ mean, thin black $=$ mean \pm 1 standard deviation . $\mathrm{t}(\% \mathrm{GC})=$ time $(\%$ gait cycle $)$.

Overall, the valgus moment generated by the brace increased during stance phase but only moderately so. The increase was most obvious between 0 and 10 percent of the gait cycle, decreasing between 10 and 30 percent of the gait cycle, i.e., during stance phase knee flexion. Between 30 and 50 percent of the gait cycle, the valgus effect of the brace increased once again.

Maximum and mean values of the orthotic moment during stance phase were used as quantitative evaluation parameters (Table 3). The mean maximum value of $0.053 \mathrm{~N} \cdot \mathrm{m} / \mathrm{kg}$ and the mean value of $0.040 \mathrm{~N} \cdot \mathrm{m} / \mathrm{kg}$ provided by the brace represent 9 and 10 percent, respectively, of the external knee moment. Minimum and maximum percentages fell between 2 and 28 percent for both parameters, indicating that the actual forces applied to the patient's leg were quite variable.

\section{DISCUSSION}

Measurement of the external genu varus moment of patients with medial knee osteoarthritis-the standard parameter for assessing knee loading-very often dem- onstrates an abnormal increase in the varus loading, even without associated changes in the knee axis $[10,13,18]$. In theory, this parameter could be useful for estimating the prognosis for osteoarthritis in the future and monitoring the effectiveness of various treatment methods. The results in this study correspond to those of earlier studies that did not show any significant influence on the external varus moment created by the knee braces [17-19], supporting the conclusion that the effect of the brace in the real world is insufficient to significantly reduce this moment. We believe that the main effect of an unloader brace, in most cases, is compensation for a portion of the external load. The consequences of such an effect are decreased internal moments (those created by the muscles and ligaments) resulting in decreased forces on the medial portion of the knee joint.

Contradictory results from other studies [14-16] may be an artifact of different investigation approaches (e.g., use of instrumented braces, unrealistically tight adjustments of the braces). Results from previous studies on the effect of braces on knee axis movements are also equivocal. While several studies report positive results [24-25], Hamann's study investigating 20 knee osteoarthritis patients found no relationship between X-ray findings and mode of action of the tested knee braces [18].

In our study, the valgus moments created by the braces were measured for the first time while in use by the patients. The mean value of $0.040 \mathrm{~N} \cdot \mathrm{m} / \mathrm{kg}$ and the mean maximum value of $0.053 \mathrm{~N} \cdot \mathrm{m} / \mathrm{kg}$ for this cohort correlate well with prior studies using different instrumented braces. Self et al. indicated values of 0.038 and $0.050 \mathrm{~N} \cdot \mathrm{m} / \mathrm{kg}$ [16], the values reported by Pollo et al. were 0.071 and $0.133 \mathrm{~N} \cdot \mathrm{m} / \mathrm{kg}$ [20], and the latest study conducted by Fantini Pagani et al. identified values of 0.030 and $0.102 \mathrm{~N} \cdot \mathrm{m} / \mathrm{kg}$ [22]. These absolute values suggest that the moment created by the brace varies, with Self at al. between 7 and 12 percent of the external moment, Pollo et al. between 6 and 20 percent, and Fantini Pagani et al. between 7 and 20 percent. These results

Table 3.

Moment generated by knee brace $\left(M_{\mathrm{br}}\right)$ and percentage of external genu varus moment $\left(M_{\chi}\right)$.

\begin{tabular}{|c|c|c|c|c|c|c|}
\hline \multirow{2}{*}{ Evaluation Parameter } & \multicolumn{3}{|c|}{$M_{\mathrm{br}}(\mathrm{N} \cdot \mathrm{m} / \mathrm{kg})$} & \multicolumn{3}{|c|}{$M_{\mathrm{br}}\left(\% M_{X}\right)$} \\
\hline & Mean & Min & Max & Mean & Min & Max \\
\hline$\overline{\operatorname{Max}}$ & 0.053 & 0.009 & 0.121 & 9 & 2 & 28 \\
\hline
\end{tabular}


compare favorably with the value of 10 percent found in this study. Larger effects with the brace calculated in some studies may reflect orthoses tightened so snugly that they would not be well tolerated by the patients in real world use.

We therefore suggest that in realistic situations, the valgus moment produced by the brace during walking may compensate on average for approximately 10 percent of the external varus moment at the knee despite considerable deviations from this mean value in individual cases. Biomechanical-model calculations suggest that a moment from the brace of this magnitude would result in a reduction of joint forces within the medial compartment on the order of 80 to $100 \mathrm{~N}$ [20]. A reduction in internal knee forces of this magnitude supports the hypothesis that the pain relief and functional improvements reported by osteoarthritis patients may be the result of the reduction in internal joint loading that the brace provides.

Alterations in the gait pattern between the WOB and WB conditions can be influenced by changes in walking speed. The increase in the vertical ground reaction force for the affected limb WB could be due to the observed mean difference of $0.09 \mathrm{~m} / \mathrm{s}$ in walking speed [26]. This relatively small change in velocity did not result in significant differences in most kinetic and kinematic gait parameters as compared with the unaffected limb. Other differences between the WB and WOB conditions for the affected limb, such as the horizontal ground reaction force and external flexion moment in the first 30 percent of the gait cycle, cannot be attributed to a walking speed difference of $0.09 \mathrm{~m} / \mathrm{s}$ [27]. Therefore, walking without the brace can be characterized by reduced walking speed accompanied by significant step-length asymmetry, reduced brake force of the arthritic limb immediately after weight acceptance, and reduced sagittal loading throughout stance phase. These findings correlate well with the results of an earlier extensive study reporting on the gait pattern of 139 knee osteoarthritis patients [28]. Gait pattern changes of this sort appear to be a protective mechanism to reduce joint pain, as illustrated by the reduction in external flexion moment, which correlates directly with a reduction in joint contact forces [28]. The present study shows that a brace can also contribute to a more symmetrical gait pattern if deviations from normal in the arthritic limb can be significantly reduced. Objective measurements of this reduction in asymmetry may correlate with the pain-reducing effect of these medical devices.

\section{CONCLUSIONS}

The results from this study show that the studied valgus-inducing knee brace can compensate for approximately 10 percent of the external genu varus moment. This compensation appears to be the main biomechanical mechanism that results in a reduction of joint force within the medial joint compartment. This biomechanical effect is an essential requirement for the reduced pain and improved overall function (such as a more symmetrical gait pattern) that result from the use of such braces. Orthotic treatment can effectively manage patients at early and middle stages of osteoarthritis or when other treatment methods are not applicable.

\section{ACKNOWLEDGMENTS}

\section{Author Contributions:}

Study concept and design: S. Blumentritt, T. Schmalz, E. Knopf. Acquisition of data: T. Schmalz, E. Knopf.

Analysis and interpretation of data: T. Schmalz, E. Knopf.

Drafting of manuscript: T. Schmalz.

Critical revision of manuscript for important intellectual content:

T. Schmalz, S. Blumentritt.

Statistical analysis: E. Knopf, T. Schmalz.

Administrative, technical, or material support: H. Drewitz.

Study supervision: S. Blumentritt, T. Schmalz.

Financial Disclosures: The authors have declared that no competing interests exist.

Funding/Support: This material was unfunded at the time of manuscript preparation.

Additional Contributions: We gratefully acknowledge Annett Elsner and John W. Michael for preparation of the manuscript.

Institutional Review: This study was approved by the Medical Faculty on the Research Ethics Committee of the University of Göttingen, and all investigations were performed in accordance with the approved protocol to ensure that ethical and humane principles were followed. Written informed consent was obtained from all participants for participation and publication, including publication of photographs and other visual depictions of subjects.

Participant Follow-Up: The authors do not plan to inform participants of the publication of this study.

\section{REFERENCES}

1. Felson DT, Lawrence RC, Dieppe PA, Hirsch K, Helmick CG, Jordan JM, Kington RS, Lane NE, Nevitt MC, Zhang Y, Sowers M, McAlindon T, Spector TD, Poole AR, Yanovski SZ, Ateshian G, Sharma L, Buckwalter JA, Brandt KD, Fries JF. Osteoarthritis: New insights. Part I: 
The disease and its risk factors. Ann Intern Med. 2000; 133(8):635-46. [PMID: 11033593]

2. Hutchins S, Jones R. Orthotic intervention in the treatment of medial compartment osteoarthritis of the knee. In: Proceedings of the 12th World Congress of the International Society for Prosthetics and Orthotics; 2007 Jul 29-Aug 3; Vancouver, Canada. Ottawa (Canada): ISPO; 2007.

3. Katsuragawa Y, Fukui N, Nakamura K. Change of bone mineral density with valgus knee bracing. Int Orthop. 1999; 23(3):164-67. [PMID: 10486029] DOI:10.1007/s002640050337

4. Horlick SG, Loomer RL. Valgus knee bracing for medial knee gonarthrosis. Clin J Sports Med. 1993;3(4):251-55.

5. Draper ER, Cable JM, Sanchez-Ballester J, Hunt N, Robinson JR, Strachan RK. Improvement in function after valgus bracing of the knee. An analysis of gait symmetry. J Bone Joint Surg Br. 2000;82(7):1001-5. [PMID: 11041589] DOI:10.1302/0301-620X.82B7.10638

6. Kirkley A, Webster-Bogaert S, Litchfield R, Amendola A, MacDonald S, McCalden R, Fowler P. The effect of bracing on varus gonarthrosis. J Bone Joint Surg Am. 1999; 81(4):539-48. [PMID: 10225800$]$

7. Hillström HJ, Brower DJ, Bhimji S, McGuire J, Whitney K, Snyder H, Zonay l, Clayburne G, Sieck M, Schumacher $\mathrm{H}$. Assessment of conservative realignment therapies for the treatment of varus knee osteoarthritis: Biomechanics and joint pathophysiology. Gait Posture. 2000;11:170-71.

8. Finger S, Paulos L. Clinical and biomechanical evaluation of the unloading brace. J Knee Surg. 2002;15(3):155-59. [PMID: 12152976]

9. Baliunas AJ, Hurwitz DE, Ryals AB, Karrar A, Case JP, Block JA, Andriacchi TP. Increased knee joint loads during walking are present in subjects with knee osteoarthritis. Osteoarthritis Cartilage. 2002;10(7):573-79.

[PMID: 12127838] DOI:10.1053/joca.2002.0797

10. Hurwitz DE, Ryals AB, Case JP, Block JA, Andriacchi TP. The knee adduction moment during gait in subjects with knee osteoarthritis is more closely correlated with static alignment than radiographic disease severity, toe out angle and pain. J Orthop Res. 2002;20(1):101-7.

[PMID: 11853076]

DOI:10.1016/S0736-0266(01)00081-X

11. Gök H, Ergin S, Yavuzer G. Kinetic and kinematic characteristics of gait in patients with medial knee arthrosis. Acta Orthop Scand. 2002;73(6):647-52. [PMID: 12553511] DOI:10.1080/000164702321039606

12. Weidenhielm L, Svensson OK, Broström LA, Mattsson E. Adduction moment of the knee compared to radiological and clinical parameters in moderate medical osteoarthrosis of the knee. Ann Chir Gynaecol. 1994;83(3):236-42. [PMID: 7857069$]$
13. Goh J, Bose K, Khoo BC. Gait analysis study on patients with varus osteoarthrosis of the knee. Clin Orthop Relat Res. 1993;(294):223-31. [PMID: 8358919]

14. Lindenfeld TN, Hewett TE, Andriacchi TP. Joint loading with valgus bracing in patients with varus gonarthrosis. Clin Orthop Relat Res. 1997;(344):290-97. [PMID: 9372780] DOI:10.1097/00003086-199711000-00029

15. Gaasbeek RD, Groen BE, Hampsink B, Van Heerwaarden RJ, Duysens J. Valgus bracing in patients with medial compartment osteoarthritis of the knee. A gait analysis study of a new brace. Gait Posture. 2007;26(1):3-10. [PMID: 16962329] DOI:10.1016/j.gaitpost.2006.07.007

16. Self BP, Greenwald RM, Pflaster DS. A biomechanical analysis of a medial unloading brace for osteoarthritis in the knee. Arthritis Care Res. 2000;13(4):191-97. [PMID: 14635273]

DOI:10.1002/1529-0131(200008)13:4<191::AIDANR3>3.0.CO;2-C

17. Hewett TE, Noyes FR, Barber-Westin SD, Heckmann TP. Decrease in knee joint pain and increase in function in patients with medial compartment arthrosis: A prospective analysis of valgus bracing. Orthopedics. 1998;21(2):131-38. [PMID: 9507265]

18. Hamann R. Klinische Studie mit ganganalytischer Untersuchung über die Wirksamkeit einer valgisierenden Knieorthese bei dem Krankheitsbild der Varusgonarthrose [Dissertation]. [Göttingen, Germany]: Georg-August-University Göttingen; 2003.

19. Otis JC, Backus SI, Campbell DA, Furman GL, Garrison G, Warren RF, Wickiewicz TL. Valgus bracing for knee osteoarthritis: A biomechanical and clinical outcome study. Gait Posture. 2000;11(2):116-17.

20. Pollo FE, Otis JC, Backus SI, Warren RF, Wickiewicz TL. Reduction of medial compartment loads with valgus bracing of the osteoarthritic knee. Am J Sports Med. 2002;30(3): 414-21. [PMID: 12016084$]$

21. Schipplein OD, Andriacchi, TP. Interaction between active and passive knee stabilizers during level walking. J Orthop Res. 1991;9(1):113-19. [PMID: 1984041] DOI:10.1002/jor.1100090114

22. Fantini Pagani $\mathrm{CH}$, Potthast W, Brüggemann GP. The effect of valgus bracing on the knee adduction moment during gait and running in male subjects with varus alignment. Clin Biomech (Bristol, Avon). 2010;25(1):70-76.

[PMID: 19758735]

DOI:10.1016/j.clinbiomech.2009.08.010

23. Kellgren JH, Lawrence J. Atlas of standard radiographs. Oxford (UK): Blackwell; 1963.

24. Komistek RD, Dennis DA, Northcut EJ, Wood A, Parker AW, Traina SM. An in vivo analysis of the effectiveness of 
the osteoarthritic knee brace during heel-strike of gait. J Arthroplasty. 1999;14(6):738-42. [PMID: 10512447] DOI:10.1016/S0883-5403(99)90230-9

25. Matsuno H, Kadowaki K, Tsuji H. Generation II knee bracing for severe medial compartment osteoarthritis of the knee. Arch Phys Med Rehabil. 1997;78(7):745-49. [PMID: 9228878] DOI:10.1016/S0003-9993(97)90083-6

26. White S, Tucker C, Brangaccio J, Lin H. Relation of vertical ground reaction force to walking speed. Gait Posture. 1996;4(2):206. DOI:10.1016/0966-6362(96)80655-2

27. Lelas JL, Merriman GJ, Riley PO, Kerrigan DC. Predicting peak kinematic and kinetic parameters from gait speed. Gait Posture. 2003;17(2):106-12.

[PMID: 12633769]

DOI:10.1016/S0966-6362(02)00060-7
28. Kaufmann KR, Hughes C, Morrey BF, Morrey M, An KN. Gait characteristics of patients with knee osteoarthritis. J Biomech. 2001;34(7):907-15. [PMID: 11410174] DOI:10.1016/S0021-9290(01)00036-7

Submitted for publication May 18, 2009. Accepted in revised form February 4, 2010.

This article and any supplementary material should be cited as follows:

Schmalz T, Knopf E, Drewitz H, Blumentritt S. Analysis of biomechanical effectiveness of valgus-inducing knee brace for osteoarthritis of knee. J Rehabil Res Dev. 2010;47(5)419-30.

DOI:10.1682/JRRD.2009.05.0067 
